\title{
El texto literario como corpus lingüístico: fraseología en novelas de García Márquez*
}

LIRIAN ASTRID CIRO**

Recepción: 13 de agosto de 2020

Aprobación: 26 de octubre de 2020

Forma de citar este artículo: Ciro, L. (2021). El texto literario como corpus lingüístico: fraseología en novelas de García Márquez.Cuadernos de Lingüística Hispánica, (37), e11282.

https://10.19053/0121053X.n37.2021.11282

* Artículo de investigación.

** Doctora en Humanidades y Educación por la Universidad de Lleida (España). Docente titular de la Escuela de Ciencias del Lenguaje, Facultad de Humanidades, Universidad del Valle, Colombia. lirian.ciro@correounivalle. edu.co. https://orcid.org/0000-0002-2778-738X 


\section{Resumen}

Presentar y clasificar algunas unidades fraseológicas fijas, halladas en novelas de Gabriel García Márquez, es el propósito en este artículo. La metodología propuesta comprende la lectura detallada, el análisis y la recolección del corpus fraseológico en algunas novelas del autor, así como la confrontación de dicho corpus con diccionarios monolingües y fraseológicos del español general, y diccionarios de colombianismos, para determinar factores semánticos y pragmáticos de estas unidades. Como resultado se elaboró un listado de fraseologismos presentes en la obra del escritor colombiano, lo que permite observar que la novelística de García Márquez es una valiosa fuente de expresiones fraseológicas. Se concluye que la obra literaria, tomada como corpus lingüístico, ofrece posibilidades para estudiar los recursos expresivos de la lengua en uso; de ahí la pertinencia de este análisis, por cuanto los estudios de fraseología en la literatura son un campo de investigación fecundo, que requieren mayor exploración en obras colombianas.

Palabras clave: corpus lingüístico, enunciado fraseológico, locución, texto literario, unidad fraseológica fija.

\section{The Literary Text as a Linguistic Corpus: Phraseology \\ In García Márquez's Novels}

\section{Abstract}

Presenting and classifying some fixed phraseological units found in García Márquez's novels is the purpose of this paper. The proposed methodology includes detailed reading, analysis and collection of the phraseological corpus in some of the author's novels, as well as the comparison of said corpus with monolingual and phraseological dictionaries of general Spanish, and dictionaries of Colombianisms, to determine semantic and pragmatic factors of these units. As a result, a list of phraseologisms present in the work of the Colombian writer was prepared, allowing observe that García Márquez's novels are a valuable source of phraseological expressions. It is concluded that literary work, taken as a linguistic corpus, offers possibilities to study the expressive resources of the language in use; hence the relevance of this analysis, since phraseology studies in the literature are a fruitful field of research that require further exploration in Colombian works.

Keywords: linguistic corpus, phraseological statement, locution, literary text, fixed phraseological units. 


\section{Le texte littéraire comme corpus linguistique : phraséologie dans des romans de García Márquez}

\section{Résumé}

Le but de cet article est de présenter et de classer certaines Unités Phraséologiques Fixes, trouvées dans les romans de Gabriel García Márquez. La méthodologie proposée comprend la lecture détaillée, l'analyse et le recensement des éléments du corpus phraséologique de certains des romans de l'auteur, ainsi que la comparaison dudit corpus avec des dictionnaires monolingues et phraséologiques d'espagnol général, et des dictionnaires de colombianismes, pour déterminer les facteurs sémantiques et pragmatiques de ces unités. En conséquence, un inventaire de phraséologismes présents dans l'œuvre de l'écrivain colombien a été préparé, ce qui nous permet de constater que les romans de García Márquez sont une source précieuse d'expressions phraséologiques. On en conclut que l'œuvre littéraire, prise comme corpus linguistique, offre des possibilités d'étudier les ressources expressives de la langue utilisée; d'où la pertinence de cette analyse, car les études de phraséologie dans la littérature sont un champ de recherche fructueux, nécessitant une exploration plus approfondie dans les œuvres colombiennes.

Mots clés: corpus linguistique, énoncé phraséologique, locution, texte littéraire, unité phraséologique fixe.

\section{o texto literário como um corpus linguístico: fraseologia em novas de García Márquez}

\section{Resumo}

Apresentar e classificar algumas Unidades Fraseológicas Fixas, encontradas em romances de Gabriel García Márquez, é o objetivo deste artigo. A metodologia proposta inclui a leitura detalhada, análise e coleta do corpus fraseológico em alguns dos romances do autor, bem como a comparação do referido corpus com dicionários monolíngues e fraseológicos de espanhol geral e dicionários de colombianismos, para determinar os fatores semânticos e pragmáticos de essas unidades. Como resultado, foi elaborada uma lista de fraseologismos presentes na obra do escritor colombiano, 0 que nos permite observar que os romances de García Márquez são uma fonte valiosa de expressões fraseológicas. Conclui-se que a obra literária, tomada como corpus linguístico, oferece possibilidades de estudo dos recursos expressivos da linguagem em uso; daí a relevância desta análise, uma vez que os estudos de fraseologia na literatura são um campo frutífero de pesquisa, exigindo uma exploração mais aprofundada nas obras colombianas.

Palavras-chave: corpus linguístico, enunciado fraseológico, locução, texto literário, Unidade Fraseológica Fixa. 


\section{Introducción}

Este artículo se deriva de un proyecto de investigación ${ }^{1}$, cuyo objetivo principal fue realizar un estudio sistemático del repertorio fraseológico de la novelística de Gabriel García Márquez, para identificar las formas en que el autor aprovecha las expresiones fijas como recursos expresivos. Con este propósito, "una vez recuperado el corpus de las expresiones fijas en sus novelas, se analizó su estructura semántica, las funciones discursivas que desarrolla y la manipulación de estas expresiones para producir efectos de sentido, así como la función pragmática que desempeña" (Díaz et al., 2009, p. 4).

En esta ocasión nos limitaremos a ejemplificar diversos tipos de unidades fraseológicas fijas (UFF, de aquí en adelante) presentes en las novelas analizadas, indagación que posibilita evidenciar el potencial de los textos literarios como corpus lingüísticos.

Un corpus es una compilación de muestras lingüísticas, recolectadas de acuerdo con unos criterios específicos y con el propósito de que sean una muestra representativa de lengua, según lo expone Pérez (2002, p. 138). En el ámbito lingüístico, los corpus textuales pueden usarse para investigar aspectos léxicos, morfológicos, sintácticos, pragmáticos, puesto que

un corpus de textos puede proporcionar muchos ejemplos del uso real de un determinado elemento lingüístico; en vez de basarse en la intuición de un lingüista o de un grupo de hablantes nativos, las conclusiones que se extraen del análisis de un corpus están basadas en casos reales del uso de la lengua. (McCullough, 2001, p. 128)

Vista de esta manera, la investigación lingüística basada en corpus facilita conocer la realidad del uso lingüístico; por tanto, el desarrollo de los corpus textuales ha posibilitado que la lingüística descriptiva dé un importante salto cualitativo (Cabré, 2003, 2007). Uno de los principales usos de los corpus textuales, además de la descripción lingüística, es que con ellos se aprende una lengua en contexto, especialmente por la posibilidad de acceder a textos auténticos; de esta forma, a través de los corpus de textos "se pueden buscar muchísimos ejemplos del uso real de un determinado elemento lingüístico y averiguar de qué maneras se emplea en lenguaje auténtico" (McCullough, 2001, p. 126). En este marco, considerar las obras literarias como textos válidos para conformar corpus lingüísticos puede parecer obvio, pues estas son, precisamente, textos auténticos; no obstante,

1 Originalmente, este proyecto fue denominado "Las expresiones fijas en la obra novelística de Gabriel García Márquez" y fue realizado por el Grupo de Estudios Lingüísticos Regionales, con el apoyo económico del Comité Central de Investigaciones (CODI) de la Universidad de Antioquia. La investigación fue desarrollada junto con los profesores Francisco Octavio Zuluaga Gómez y Viviana Díaz Orozco. Como resultado principal de este proyecto se publicó el libro Dichos, refranes y locuciones en las novelas de Gabriel García Márquez (2019). 
Son muchas las voces que se han alzado en contra de considerar la literatura como muestra válida para el análisis de la lengua de una comunidad sociocultural. Ya en 1929 Beinhauer sostenía que los textos literarios, aunque traten de imitar la lengua coloquial, son manifestaciones artísticamente moldeadas y engalanadas por los escritores. Según esta afirmación, el lenguaje literario tendería por naturaleza a separarse y diferenciarse del lenguaje común con una voluntad estética. Esto, en principio, lo invalidaría como corpus de estudio del que se pudieran extrapolar las conclusiones sobre los valores semánticos, sociolingüísticos 0 , en nuestro caso, pragmáticos, que otorga el hablante real a sus usos cotidianos (...). (Gancedo, 2016, p. 165)

A pesar de ello, Gancedo (2016, p. 166) afirma que el estatuto de ficción no impide el análisis pragmático, puesto que muchos usos lingüísticos cotidianos son también ficticios y para ello cita ejemplos como las mentiras, la ironía y los chistes. Para superar las limitaciones de los textos literarios como corpus lingüísticos, esta autora señala la importancia de definir claramente los criterios para seleccionar los textos que integren dicho corpus, entre otros, los más relevantes, a juicio de Gancedo (2016), serían la "verosimilitud histórica y sociolingüística y que el tiempo de la historia sea coetáneo al tiempo de la escritura, de manera que las intuiciones como hablante del autor sean adecuadas (...)” (p. 171).

A propósito de la verosimilitud en el texto literario, esta se nutre de dos aspectos: la lengua y la historia social, lo que no implica que la literatura como tal deba estar limitada por el hecho social que la engendra, por cuanto "el texto (...) está doblemente orientado: hacia el sistema significativo en que se produce (la lengua y el lenguaje de una época y una sociedad precisas) y hacia el proceso social en que participa en cuanto discurso (...)» (Kristeva, 1978a, p. 11). Esta doble orientación exige observar las relaciones entre ambos aspectos y mostrar de qué manera confluyen para dotar de significado al discurso literario.

El concepto de verosimilitud de esta autora es valioso, porque se retoma tanto desde el aspecto semántico como desde el sintáctico; así, se afirma que es en el texto literario y en su estructura retórica donde recae el sentido del mismo. Otro elemento clave en relación con el concepto aludido es, en primera instancia, el planteamiento acerca de la repetición como una función fundamental de lo verosímil, elemento que se puede rastrear claramente en la obra de García Márquez, tanto desde los elementos temáticos como desde los recursos expresivos, entre ellos las UFF. En cuanto a esto, la frase "como función semántica no es en totalidad descomponible en unidades lexicales, semánticas o gramaticales. Es un proceso, una acción a través de la cual se encarna el sentido; no se reduce pues a una acumulación del sentido de las palabras expresadas (...)” (Kristeva, 1978b, p. 148), definición que se asemeja claramente a la de las UFF.

En este punto es necesario precisar la definición de las UFF. Se trata de expresiones estereotipadas, conformadas por combinaciones estables de palabras 
(Corpas, 1996, p. 15), que son reproducidas en el discurso. Corresponden al conjunto de todo aquello que en una tradición lingüística aparece de forma fija y cristalizada (Coseriu, 1986, p. 113). Se puede hacer una división básica de estas UFF en locuciones (nominales, verbales, adjetivas, adverbiales, conjuntivas, preposicionales, interjectivas) y enunciados fraseológicos (fórmulas pragmáticas y paremias - refranes, citas célebres, sentencias, entre otros-).

Las UFF son de gran interés, entre otros aspectos, porque reflejan la cosmovisión de cada cultura en la que se enmarcan, como es el caso de los refranes, los cuales sirven para aclarar o explicar, para apoyar una postura, para afirmar o para justificar una decisión (Sevilla, 2000; Tarnovska, 2003). Las UFF tienen una carga cultural muy significativa que se explota en la construcción textual y discursiva, y se activan en el receptor, sintetizando un saber sociocultural y trasladando todo el sentido de la frase al contexto.

Teniendo en cuenta lo anterior, para el análisis se toma como corpus la obra novelística de García Márquez, por ser este el autor más universal de Colombia; además, se considera que el análisis fraseológico posibilita una aproximación significante a la obra literaria, en este caso a las novelas del escritor colombiano. Se parte de la idea de que los mecanismos lingüísticos de los textos literarios no difieren significativamente de cualquier otro tipo de discurso; en este sentido, no obstante tener ciertas características específicas, el discurso literario no se diferencia sustancialmente del discurso cotidiano. Como lo plantea Fernández (2000): "no es un tipo especial de lenguaje, sino un uso especial de éste, determinado por el contexto en que se produce" (p. 107).

Dicha semejanza entre el discurso literario y el discurso común o cotidiano es lo que permite hablar del carácter de verosimilitud del primero; como indica Van Dijk (1987), si se considerara la literatura como un discurso especial, cada obra exigiría unas condiciones de recepción especiales y, por ende, todo texto literario sería un tratado lingüístico nuevo y una concepción de la realidad particular, totalmente alejada de aspectos reconocibles por el lector, lo cual no tendría sentido.

Si se tiene en cuenta que el discurso literario es, en esencia, igual a cualquier otro tipo de discurso, se puede afirmar que en él encontramos los diferentes componentes de la lengua en uso, por lo cual puede servir de corpus para el estudio de los fenómenos lingüísticos. Según Bolaños et al. (1990, p. 48), el discurso literario es un proceso de imitación "del uso normal del lenguaje, en el que los actos de habla literarios son cuasi-actos de habla, sin ninguna fuerza ilocutiva". Por su parte, Searle (1996) indica que los textos literarios simulan la realización de estas aserciones y que dicha simulación es posible

por la existencia de un conjunto de convenciones que suspenden el funcionamiento normal de las reglas que relacionan a los actos ilocucionarios con el mundo. En este sentido, [...] narrar relatos, en realidad, es un juego del lenguaje particular; para jugarlo se requiere un conjunto de convenciones 
particulares, aunque estas convenciones no son reglas de significado; y este juego no está en perfecto acuerdo con los juegos ilocucionarios del lenguaje, sino que es una forma parásita de éstos. (p. 169)

Según Van Dijk (1987), el discurso literario está conformado por "quasiaserciones [sic], aserciones que no son verdaderas en el mundo real y que, por lo tanto, no deben ser consideradas en serio como información relevante para la interacción dentro del mundo real y el contexto comunicativo" (p. 179). Plantea, así mismo, que las aserciones literarias son declaraciones contraevidentes, en las cuales el escritor, como emisor, no pretende que su enunciado sea interpretado por un oyente/lector como empíricamente verdadero (como en las mentiras), ni tampoco cree, él mismo, que su enunciado sea empíricamente verdadero (como en los errores). Es así que el discurso literario es moralmente contraevidente y pragmáticamente simulado como tal por un hablante que no niega su contrafactualidad en un acto de habla. Como ejemplo, obsérvese la siguiente cita tomada de Cien años de soledad:

Fernanda sintió que un delicado viento de luz le arrancó las sábanas de las manos y las desplegó en toda su amplitud. Amaranta sintió un temblor misterioso en los encajes de sus pollerines y trató de agarrarse de la sábana para no caer, en el instante en que Remedios, la bella, empezaba a elevarse. Úrsula, ya casi ciega, fue la única que tuvo serenidad para identificar la naturaleza de aquel viento irreparable, y dejó las sábanas a merced de la luz, viendo a Remedios, la bella, que le decía adiós con la mano. (García Márquez, 2007, p. 273)

En este fragmento, el autor no pretende que el lector tome el hecho de la ascensión al cielo de Remedios, la bella, como verídico. Ambos, emisor y receptor, parten del supuesto de que en la comunicación literaria no se aplica al valor de verdad, en lo que a real se refiere; aquí se presenta un acto de cooperación, o "pacto ficcional" en palabras de Eco (1996), donde no se pone en tela de juicio lo enunciado por el autor ni lo interpretado por el lector.

En otra dirección, los fraseologismos en los textos literarios tienen funciones inherentes y no inherentes; las primeras "dependen de las propiedades de los fraseologismos y se presentan, por tanto, cada vez que éstos se empleen en el discurso" (Zuluaga, 1997, p. 50); estas son: función fraseológica, connotación o evocación, función icónica, función lúdico-poética. Por su parte, las funciones textuales no inherentes no están determinadas "por rasgos de la estructura misma de las UF, [más bien] se definen como efectos de sentido producidos por su contextualización” (Zuluaga, 1997, p. 58).

Los planteamientos anteriores permiten evidenciar que la obra literaria se puede tomar como corpus para el estudio de los recursos expresivos de la lengua, puesto que, entre otros argumentos, "el texto literario ofrece la posibilidad de acudir a él cuantas veces sea necesario. (...) En este sentido (...) es inmutable, no cambia lingüísticamente" (López, 2012, p. 28), lo cual lo hace idóneo para conformar un corpus, pues es testimonio del uso lingüístico, tal y como se reseña en la siguiente cita 
en la que se enuncian las investigaciones de varios autores en las que se entrelazan la literatura y la lingüística, específicamente desde la pragmática:

el propio Goffman (1959) utilizó algunos pasajes de la novela Happy holiday abroad de Samsom para ejemplificar comportamientos relacionados con la imagen. También acudieron a la literatura, entre otros, Brown y Gilman (1989), Culpeper (1996) (quienes aplicaron sus análisis a textos de Shakespeare) 0 Haverkate (2001), quien analizó aspectos de cortesía en La Celestina y El Quijote. Más recientemente, Navarro Gala (2004) estudió las fórmulas de tratamiento en La Segunda Celestina, Pedroviejo Esteruelas (2004) hizo lo propio en Bajarse al moro e Historia de una escalera mientras que Zamora Salamanca (2014) analiza actividades de imagen en textos narrativos como Anatomía de un instante (...). (Gancedo, 2016, p. 164)

Como antecedentes directos de esta investigación hallamos algunos trabajos que se aproximan a la temática. De Jonge (2001) estudió el uso del subjuntivo en español a partir del cuento Los funerales de la Mamá Grande; Ruiz-Gurillo (1997) analizó las locuciones adverbiales en Cien años de soledad; Palma (2010) hizo también un estudio sobre el uso frecuente de locuciones en Cien años de soledad, uso que, a juicio de la autora, contribuye a crear un ambiente de desmesura en los personajes y situaciones. Según esta autora, la focalización en las locuciones de esta novela se debe a "su carácter no composicional y a menudo metafórico y también porque constituyen el grupo más nutrido" (p. 2). Asimismo, se encuentra el artículo "Las frases hechas en la Crónica de una muerte anunciada de Gabriel García Márquez y su traducción árabe” de Kareem-Alshamary (2018). A decir de este autor, esta novela es una de las mejores obras de García Márquez, la cual se caracteriza "por su estilo periodístico en el que podemos distinguir dos registros: el de la lengua culta con el que se comunica el autor y el de la lengua familiar o coloquial cargada de frases hechas, y palabras vulgares, de elementos irónicos, simbólicos y mágicos. La primera característica a destacar [sic] es el uso abundante de expresiones fraseológicas, sobre todo las frases hechas (...)" (Kareem-Alshamary, 2018, p. 911). También se reseña el libro La lengua ladina de García Márquez, de De Oliveira (2007); este es un diccionario que contiene "regionalismos colombianos, colombianismos e hispanoamericanismo, como también palabras de uso poco común, que no hacen parte de un vocabulario usual" (p. 15). Al respecto, se resalta "la cantidad de expresiones que utiliza el escritor colombiano, la variedad maravillosa de su léxico, la maestría exhibida en el oficio, la destreza de que hace gala al construir su universo literario a punta de palabras" (De Oliveira, 2007, p. 10).

Por otra parte, es necesario considerar que

En artículos de revistas especializadas del área — como Paremia, Proverbium (International Proverb Scholarship) — se ha observado que la investigación fraseológica sobre obras clásicas de la literatura occidental es muy amplia; inclusive se han analizado obras colombianas como El Cristo de espaldas de Eduardo Caballero Calderón. Esta cantidad de artículos contrasta con la poca producción de estudios paremiológicos aplicados a obras literarias 
colombianas en nuestro medio, salvo los realizados sobre la obra de Tomás Carrasquilla, hace ya más de 25 años, por Néstor Villegas Duque y Jaime Sierra García, y sobre El Cristo de espaldas, por Luis Iván Bedoya y Augusto Escobar (...). (Zuluaga et al., 2019, p. 9)

Es precisamente lo anterior lo que justifica esta investigación. Es claro que hacen falta más estudios al respecto, tanto de la obra de Gabriel García Márquez como la de otros escritores colombianos. Hacemos énfasis en que en este artículo solo se busca presentar, de forma esquemática, ejemplos de diferentes UFF retomadas de la obra novelística del escritor aracateño, pero creemos que este es un primer paso para profundizar en el ámbito colombiano en la interrelación entre lingüística y hermenéutica literaria, así como en las conexiones y cruces entre la lexicografía, la fraseología y la pragmática.

\section{Metodología}

Para la compilación del corpus fraseológico en la obra de García Márquez, se ha realizado la lectura detenida y detallada de nueve novelas del autor. Luego de retomar algunas de las expresiones fijas halladas, se ha hecho la catalogación de acuerdo con el tipo de UFF. Finalmente, se ha confrontado el corpus con diccionarios monolingües y fraseológicos del español general, y con diccionarios de colombianismos, para determinar elementos semánticos y pragmáticos de las expresiones fijas. los siguientes:

Entre algunos de los diccionarios empleados para el contraste, se encuentran

- Diccionario de la Lengua Española (RAE, 2014); diccionario, por excelencia, del español general.

- Nuevo Diccionario de Colombianismo (NDCol) de Haensch y Werner (1993), uno de los diccionarios representativos del español de Colombia.

- Diccionario Fraseológico Documentado del Español Actual. Locuciones y modismos españoles (DFEA) de Seco, Andrés y Ramos (2004), diccionario fraseológico de gran representatividad, aunque restringido al español peninsular.

A continuación, se enuncian las novelas tomadas como corpus²:

- Memoria de mis putas tristes (2004).

- La bojarasca (2003).

- El otoño del patriarca (2003).

2 Se presenta el año de la edición de la cual se ha partido. 
- Crónica de una muerte anunciada (2003).

- El coronel no tiene quien le escriba (1999).

- Del amor y otros demonios (1994).

- El general en su laberinto (1989).

- El amor en los tiempos del cólera (1985).

- Cien años de soledad (2007).

Se considera que partimos de una muestra válida que permite observar la riqueza fraseológica de la novelística garciamarquiana, motivo por el cual se ha escogido una metodología cualitativa y un enfoque descriptivo, por ser nuestro principal objetivo establecer una caracterización de las UFF encontradas.

\section{Resultados}

Como resultado se elaboró un repertorio de fraseologismos presentes en novelas de Gabriel García Márquez. En este apartado se ejemplifican los diversos tipos de UFF identificadas. Se hace énfasis en que optamos por la denominación técnica unidades fraseológicas fijas, por cuanto: 1 . Son unidades en el sentido de que hay que tomarlas como un todo indivisible; así son aprendidas y reproducidas; 2 . Son fraseologismos por cuanto, si se tiene en cuenta su estructura sintáctica, se ubicarían en el nivel de la frase; 3 . Son fijas porque, justamente, la fijación que las afecta es en definitiva su rasgo constitutivo como un tipo de entidades lingüísticas particulares. Tomamos su clasificación en locuciones y enunciados fraseológicos.

A continuación, se definen y ejemplifican diversos tipos de UFF, a partir de las expresiones halladas en las novelas de García Márquez, para lo cual se presenta un microcontexto de una de las novelas en donde aparece el fraseologismo.

\section{Locuciones}

Estas se pueden definir como "las agrupaciones más o menos fijas de dos 0 más palabras que funcionan como elementos oracionales, tal como lo hacen las palabras individuales (nombre o sustantivo, adjetivo, verbo, adverbio, preposición, conjunción)" (Seco et al., 2004, p. XVI). Las locuciones se combinan con otros elementos en el interior de la frase, por tanto, requieren un contexto verbal inmediato (Zuluaga, 1992, p. 129). Estas unidades son caracterizadas por Corpas (1996) con los siguientes rasgos: fijación interna, unidad de significado y fijación externa pasemática.

Según la Nueva Gramática de la Lengua Española (NGLE) (2009), las locuciones son grupos de palabras que

constituyen una sola pieza léxica, y ejercen la misma función sintáctica que la categoría que les da el nombre. Así, las LOCUCIONES ADJETIVAS equivalen, 
con diversos grados de proximidad, a los adjetivos (de cuidado viene a significar 'peligroso'); las LOCUCIONES PREPOSICIONALES equivalen a las preposiciones (a bordo de se acerca a sobre, o a en en ciertos contextos); las LOCUCIONES ADVERBIALES equivalen a los adverbios (a rajatabla se aproxima a estrictamente), y las LOCUCIONES CONJUNTIVAS equivalen a las conjunciones (si bien alterna con aunque). (Real Academia Española y Asociación de Academias de la Lengua Española, 2009, p. 53)

A continuación, ejemplificamos las locuciones significantes; es decir, se incluyen las locuciones nominales - grupo de palabras que constituye una sola pieza léxica y que equivale a un nombre o sustantivo (NGLE, 2009)_; verbales — grupo de palabras equivalente a un verbo - , adjetivales - grupo de palabras similar a los adjetivos en su función sintáctica (NGLE, 2009) — y adverbiales — grupo de palabras que equivalen a un adverbio (NGLE, 2009) —; y se excluyen las locuciones preposicionales, conjuntivas e interjectivas. Solo se presenta un ejemplo y un microcontexto, a modo de ilustración.

- Locución nominal:

abogado del diablo. loc. nom. Contradictor de buenas causas (DLE, 2014).

“-imagínese, padre, qué presentimiento de santa, pero a pesar de los testimonios febriles de los vecinos el abogado del diablo encontró más vestigios de timidez que de humildad entre los escombros (...)" (El otoño del patriarca, 2003, p. 221).

- Locución verbal:

echar de menos. loc. verb. Extrañar.

“-Fermina Daza siguió abriendo el balcón por las mañanas durante varios meses, y siempre echaba de menos el fantasma solitario que la acechaba en el parquecito desierto, veía el árbol que fue suyo, el banco menos visible donde se sentaba a leer pensando en ella, a sufrir por ella (...)" (El amor en los tiempos del cólera, 1985, p. 280).

- Locución adjetiva:

de doble filo. loc. adj. Que puede obrar en contra de lo que se pretende (DLE, arma de doble).

“-[...] uniformó a sus antiguos alumnos, exacerbados por sus proclamas incendiarias, y los dejó andar armados por las calles para dar a los forasteros la impresión de invulnerabilidad. Fue un truco de doble filo, porque el gobierno no se atrevió a atacar la plaza durante diez meses, pero cuando lo hizo descargó contra ella una fuerza tan desproporcionada 
que liquidó la resistencia en media hora" (Cien años de soledad, 2007, p.106).

- Locución adverbial:

a gatas. loc. $a d v$. Dicho de ponerse 0 andar una persona: con pies $\mathrm{y}$ manos en el suelo, como los gatos y demás cuadrúpedos (DLE, 2014).

“-El sol avanzó hacia el centro de la escueta habitación construida con tablas de cepillar. Después de buscar inútilmente por todas partes, el abogado se puso a gatas, bufando, y cogió un rollo de papeles bajo la pianola" (El coronel no tiene quien le escriba, 1999, p. 48).

\section{Enunciados fraseológicos}

Según Zuluaga (1992, p. 129), los enunciados fraseológicos son aquellas UFF que constituyen por sí mismas enunciados completos; es decir, que no necesitan de un contexto verbal inmediato para constituir una expresión de sentido completo. De acuerdo con la NGLE (2009, p. 73), los enunciados se caracterizan, entre otros aspectos, por los siguientes: poseen valor comunicativo, constituyen por sí mismos mensajes, tienen autonomía sintáctica y se asocian con actos verbales. Zuluaga (1992) clasifica los enunciados fraseológicos en fórmulas pragmáticas y paremias. Estas últimas incluyen, entre otros, los refranes, las citas célebres, las sentencias y los dialogismos.

\section{Las fórmulas pragmáticas.}

Estas unidades tienen fijación pragmática, es decir, están ligadas a la interacción verbal; en este sentido, indican cuando una expresión se asocia con una actitud específica del hablante hacia aquello que se refiere 0 al efecto buscado (despectivo, enfático, cortés, irónico). Asimismo, "se usan o sirven para, por ejemplo, saludar (¿Cómo amaneció?), despedirse (Hasta mañana), agradecer (Muchas gracias), es decir, realizan [sic] actos de habla..." (Zuluaga et al., 2019, p. 23).

Teniendo en cuenta el valor pragmático de las fórmulas rutinarias, la clasificación que se presenta parte de la tipología de los actos de habla (Searle, 1979). A continuación se presentan algunos ejemplos de las fórmulas identificadas.

\section{- Fórmula de aceptación:}

Ni más faltaba. fór. aceptación de un ofrecimiento usada para manifestar la disposición favorable al cumplimiento de lo que se ha requerido (DEL, 2014, no faltaba más). $\|$ fór. de aceptación de un ofrecimiento 0 invitación planteados en una construcción negativa: - no vayan a faltar a la fiesta. —Ni más faltaba, alli estaremos. 
“-Fermina Daza lo notó, y le hizo prometer en voz baja que asistiría al entierro. Por supuesto que lo haría, dijo él, aliviado, ni más faltaba" (El amor en los tiempos del cólera, 1985, p. 58).

- Fórmula de advertencia:

Piénselo bien. fór. advertencia o recomendación.

"—No se equivoque — le dijo—- Yo me aparto de todo esto cuando usted quiera, pero piénselo bien. Florentino Ariza, que en efecto no lo había pensado, lo pensó entonces tan bien como pudo, y le entregó sus armas" (El amor en los tiempos del cólera, 1985, p. 256).

- Fórmula de agradecimiento:

Gracias, Dios mío. fór. de agradecimiento.

"-Creyó morir de alegría. Sin tiempo para pensarlo se lavó las manos de cualquier modo, murmurando: "Gracias, Dios mío, gracias, qué bueno eres", pensando que todavía no se había bañado por las malditas berenjenas que le había pedido Hildebranda sin decirle quién era el que venía a almorzar..." (El amor en los tiempos del cólera, 1985, p. 348).

- Fórmula de amenaza:

Vas a saber quién es quién. Bajo la forma van/vas a saber quién es quién se usa como fór. amenaza, como se puede ver en la muestra. Amenaza con evidenciar el lado negativo de alguien.

"a pesar del amparo de mi autoridad, hijos de puta, a pesar de mis telegramas terminantes, carajo, pero ahora van a saber quién es quién, roncaba, masticaba espuma de hiel no tanto por la rabia de la desobediencia como por la certeza de que algo grande le ocultaban si se habían atrevido a contrariar las centellas de su poder..." (El otoño del patriarca, 2003, p. 225).

- Fórmula de asentimiento:

Dígamelo a mí. fór. asentimiento. Enfatiza al interlocutor la convicción de lo que se dice o se aconseja. || Expresa que la persona mencionada en el pronombre tiene, por su experiencia en la materia, particular autoridad para opinar sobre lo que acaba de oír (DFEA, dímelo a mí - que me lo digan a $m \hat{\imath})$.

"Se sentirá forastero en todas partes, y eso es peor que estar muerto". Lo miró directo a los ojos, se puso la mano abierta en el pecho, y concluyó: "Dígamelo a mí" (El general en su laberinto, 1989, p. 225). 
- Fórmula de compromiso:

Palabra de honor/hombre. fór de compromiso con que se empeña la palabra. \| "En boca de un hombre o con referencia a él, como aseveración formal de la dicho" (DFEA, 2004).

“- ...y fue por eso que lo hicimos mi general, palabra de bonor, y entonces él exhaló una bocanada de alivio, ordenó que les dieran de comer, que los dejaran descansar esa noche y que por la mañana se los echen a los caimanes..." (El otoño del patriarca, 2003, p. 59).

- Fórmula concesiva:

Soy todo suyo. fór. concesiva enf. con que el hablante ponderativamente le expresa al interlocutor la disponibilidad para concederle lo solicitado.

"Apenas terminados los formalismos iniciales, ella fue directo a sus asuntos: "Vengo a suplicarle un favor". 'Soy todo suyo', dijo él" ( $E l$ general en su laberinto, 1989, p. 88).

- Fórmula de condolencia:

Lo siento en el alma. fór. de condolencia o disculpa.

"En la confusión de los aplausos finales, miró a Florentino Ariza con una aflicción sincera.

—Créame que lo siento en el alma —le dijo.

Florentino Ariza se impresionó, no por las condolencias que en realidad merecía, sino por el asombro de que alguien conociera su secreto" ( $E l$ amor en los tiempos del cólera, 1985, p. 268).

- Fórmula de desaprobación:

¿Qué maravilla! fór. desaprobación iró. Usada para manifestar enfáticamente desaprobación o reproche.

"Lo primero, claro, fue desaparecer mientras se aplacaba el escándalo. ¿Qué maravilla! Una luna de miel para tres, ellos dos en la cama, y Rosa Cabarcas en una terraza de lujo disfrutando de su impunidad feliz" (Memoria de mis putas tristes, 2004, p. 90).

- Fórmula desiderativa:

No lo permita Dios. fór. desiderativa relig. Expresa el deseo de que suceda (o no) lo que se menciona a continuación (prop con que) (DFEA, 2004). 
“_....pero piensa en el futuro, que no te quiero ver pidiendo la caridad con un sombrero en la puerta de una iglesia si mañana o más tarde no lo permita Dios te quitan de la silla en que estás sentado, si al menos supieras cantar, o si fueras arzobispo, o navegante, pero tú no eres más que general..." (El otoño del patriarca, 2003, p. 97).

- Fórmula de despedida:

Duerme(a) con Dios. fór. despedida relig. Usada en la noche.

“-...que pase buena noche, murmuró, como siempre, aunque nadie le contestaba desde hacía tanto tiempo muy buenas noches hijo, duerme con Dios, se dirigía a su dormitorio con la lámpara de salir corriendo..." (El otoño del patriarca, 2003, p. 319).

- Fórmula de disculpa:

Con mis respetos. fór disculpa form. Acompaña a una afirmación que podría resultar ofensiva o molesta para el oyente o para la persona o cosa que se menciona (DFEA, 2004). $\|$ En contexto argumentativo se usa para introducir un disentimiento.

“- _...Se estiró sentado en la hamaca, bostezó y dio gracias al Señor por el nuevo día. Delaura no había perdido el hilo.

—Con mis respetos, padre mío, — dijo, — no creo que esa criatura esté poseída..." (Del amor y otros demonios, 1994. p.123).

- Fórmula enfática:

Pase lo que pase. fór. enfática. Se usa para ratificar enfáticamente una decisión, una afirmación, una orden o una propuesta (DFEA, 2004).

"—Cuando volvió a hablar, su voz y su ánimo habían cambiado. 'No se preocupe', dijo. "Pase lo que pase nos iremos para Europa, aunque sólo sea por no privar a su padre del gusto de verlo..." (El general en su laberinto, 1989, p. 72).

- Fórmula de felicitación:

iEnhorabuena! fór. felicitación || Interj. Se usa para felicitar a alguien (DFEA, 2004).

"Él la reconoció por los pasos y le habló sin abrir los ojos. 'Va a haber una insurrección', dijo. Ella no disimuló el rencor con la ironía. 'Enborabuena', dijo. 'Puede haber hasta diez, pues usted da muy buena acogida a los avisos'. 'Sólo creo en los presagios', dijo él” (El general en su laberinto, 1989, p. 59). 
- Fórmula de insulto:

hijo de puta. fór: insulto vulg.

"- Lorenzo Daza tuvo que mirarlo de lado, como los loros, para encontrarlo con el ojo torcido. No pronunció las tres palabras sino que pareció escupirlas sílaba por sílaba:

—iHi-jo-de-pu-ta!" (El amor en los tiempos del cólera, 1985, p. 116).

- Fórmula de negación:

Ni de vainas. fór. negación enf. coloq. De ninguna manera (NDCol, 1993).

“-... no se encontró con el anciano lelo que se quedaba dormido en las audiencias sino con el antiguo carácter de bisonte que sin pensarlo un instante contestó que ni de vainas, que no se iba..." (El otoño del patriarca, 2003, p. 176).

- Fórmula de petición:

por favor. fór. petición cortés para hacer una solicitud o petición.

“-Antes de ocuparse de la niña le rogó de muy buen tono a la guardiana que saliera de la celda.

Luego, sin la misma dulzura, le dijo a la abadesa:

—Usted también, por favor.

—Bajo su responsabilidad, —dijo ella" (Del amor y otros demonios, 1994, p. 112).

- Fórmula de rechazo:

Primero muerto. fór. rechazo enf. Se profiere ante una propuesta 0 una situación hipotética que se considera inaceptable; "se usa como negación enfática ante una propuesta o una posibilidad futura" (DFEA, 2004, antes muerto). || Usada generalmente en la construcción: primero muerto que...

“-Temblé por Delgadina. Lo mejor será que te la lleves tú, me dijo Rosa Cabarcas. Primero muerto, le dije con la saliva helada. Ella lo percibió y no pudo ocultar su desdén: iEstás temblando!" (Memoria de mis putas tristes, 2004, p. 79).

- Fórmula de recibimiento: 
Esta es tu/su casa. fór. recibimiento ritual. La usa el dueño de la casa para invitar al visitante a hablar o actuar con libertad o sin cumplidos (DFEA, 2004, estás en tu casa).

"La mujer se sentó frente a él y le habló en un castellano difícil.

—Esta es su casa, doctor — dijo- No lo esperaba tan pronto" (El amor en los tiempos del cólera, 1985, p. 23).

- Fórmula de réplica:

¡Qué [...] ni qué carajo!fór réplica coloq. con que se rechaza enfáticamente lo que dice el interlocutor por considerarlo desproporcionado 0 absurdo. || UFF con casilla vacía.

“-Escapó por milagro de una ejecución sumaria acusado de ser un espía que mandaba mensajes en clave de sol a los buques liberales que merodeaban por las aguas vecinas.

—Qué espía ni qué carajo — dijo Florentino Ariza—, yo no soy más que un pobre enamorado" (El amor en los tiempos del cólera, 1985, p. 101).

- Fórmula de reproche:

iA buena hora! fór. reproche iró. Referida a un hecho esperado que ocurre demasiado tarde.

“-Petra Cotes lo vio llegar sin sorpresa, sin alegría ni resentimiento, y apenas se permitió una sonrisa irónica.

—iA buena bora! —dijo.

Estaba envejecida, en los puros huesos..." (Cien años de soledad, 2007, p. 312).

- Fórmula de ruego:

(se lo ruego) por el amor de Dios. fór. exhortativa de ruego. relig. para pedir con encarecimiento, excusarse con humildad o esforzar una súplica cualquiera (DEL, 2014, por amor de Dios). \| Se aplica también a variadas situaciones: rechazo, aquiescencia, sorpresa... (Corpas, 1996).

"Ambos agarraron entonces el rollo de periódicos, y Pedro Vicario empezó a levantarse.

- Por el amor de Dios — murmuró Clotilde Armenta_. Déjenlo para después, aunque sea por respeto al señor obispo" (Crónica de una muerte anunciada, 2003, p. 25). 
- Fórmula de saludo:

¿Cómo pasó la noche? fór. saludo. Usada como salutación en horas de la mañana.

"en cambio ahora no había nadie que le pidiera nada, nadie que le dijera al menos buenos días mi general, cómo pasó la noche..." (El otoño del patriarca, 2003, p. 344).

\section{El refrán.}

Es una UFF prototípica, que representa muy bien lo que se entiende como discurso repetido. En seguida se presenta una definición de refrán que se considera muy completa, pues indica tanto su propósito como su origen y composición:

[el refrán es] un dicho agudo y sentencioso de uso común, que refiere una enseñanza, un hecho de la experiencia 0 un pensamiento, conteniendo un componente simbólico o metafórico, tiene un origen común, es anónimo y el pueblo es quien lo crea, lo difunde, lo modifica, lo amplía e incluso lo olvida. El refrán es una frase generalmente breve que expresa una sentencia, un dicho 0 un consejo útil sobre la vida cotidiana siendo en la mayoría de los casos una expresión de la sabiduría popular (...). (Díaz \& Hernández, 2010, p. 4)

El refrán posee una gran carga sociocultural y pragmática; en este marco,

se entiende (...) como sentencia lingüística concreta, realizada por un hablante en una situación comunicativa; se define dentro de una teoría pragmática, y su interpretación depende de su contenido semántico, pero especialmente de las condiciones contextuales de emisión, y se valora según parámetros pragmáticos de adecuado e inadecuado / efectivo e inefectivo (...). (Ramírez \& Álvarez, 2006, p. 222)

Según Zuluaga (1980, p. 200), los refranes gozan de autonomía textual y se evidencian como minitextos, en el sentido de que están libres de toda dependencia anafórica, catafórica o deíctica, del contexto lingüístico o extralingüístico; es decir, contienen por sí mismos un mensaje o información con sentido completo.

A continuación, presentamos algunos ejemplos de los siguientes tipos de refranes: axiológicos (valores), doxásticos (opiniones o ideologías), epistémicos (conocimientos culturales), descriptivos (tipificación de conductas o hechos).

Refranes axiológicos. Este tipo de refranes son muestras evaluativas de opiniones, actitudes e ideologías, y destacan los valores socialmente esperados. En este sentido, dichos refranes son típicamente sentenciosos, ya que brindan consejos, recomendaciones y máximas de conducta moral (por ejemplo: de gente bien nacida es ser agradecida). Por ello la afirmación: "son la expresión de valores de una sociedad determinada, entendiendo por estos las propiedades positivas del 
mundo personal y social que son consideradas metas ideales por las cuales amerita esforzarse" (Zuluaga et al., 2019, p. 21). Algunos refranes de naturaleza axiológica encontrados en las novelas de García Márquez son: a buen hambre no hay mal pan; lo que por agua viene, por agua se va; no/nunca digas de esa agua no beberé; la cara del santo bace el milagro. Ahora, un ejemplo con microcontexto:

la unión hace la fuerza. refr. De naturaleza axiológica y sentido literal, que invoca la solidaridad.

“- _...se llenó los pulmones de un aire abrasante y pronunció la sentencia como si acabara de inventarla:

\section{-la unión bace la fuerza.}

—En este caso no la hizo — dijo el coronel, por primera vez dándose cuenta de su soledad- Todos mis compañeros se murieron esperando su correo" (El coronel no tiene quien le escriba, 1999, p. 45).

Refranes doxásticos. Este tipo de refranes pueden poner de manifiesto las actitudes que se tienen hacia otros grupos (por ejemplo: cachaco, paloma y gato, tres animales ingratos), por cuanto "son la expresión de opiniones o creencias evaluativas, y por ello pueden variar en función de la concepción ideológica de los grupos sociales" (Zuluaga et al., 2019, p. 20). Seguidamente, un ejemplo que, aunque no muestra una creencia sobre un grupo social en particular, sí aconseja acerca de cómo actuar frente a una situación, de acuerdo con las características de la sociedad colombiana, remitiendo, específicamente, a un ámbito profesional como lo es el derecho:

Más vale un mal acuerdo/arreglo que un buen pleito. refr: doxástico y sentido literal. Aconseja que en situaciones conflictivas es preferible una solución que no nos satisface completamente a un conflicto de grandes proporciones. Relativo, generalmente, al ámbito jurídico. [más valía un buen acuerdo que mil pleitos ganados]. Desautomatizada por combinación: adición e inversión del orden de los constituyentes.

"En una de sus escasas crisis de arrepentimiento, discutiendo entre bromas y veras con los dueños de casa, los sorprendió con la sentencia de que más valía un buen acuerdo que mil pleitos ganados" (El general en su laberinto, 1989, p. 235).

Refranes epistémicos. Estos refranes "son la expresión de conocimientos acumulados a través de la experiencia, que se suelen considerar como fuente de conocimiento en dominios muy variados, tales como la naturaleza, el tiempo y el espacio" (Zuluaga et al., 2019, p. 19); es decir, las creencias que parten de hechos culturales y datos comúnmente aceptados (por ejemplo: en abril, aguas mil; de tal palo, tal astilla). A continuación, dos ejemplos en la novelística de García Márquez: mujer enferma, mujer eterna, y loro viejo no aprende a hablar. Ilustramos de manera detallada este último: 
Loro viejo no aprende a hablar refr. epistémico y sentido figurado. Manifiesta la incapacidad que la edad ocasiona para el aprendizaje de algunas cosas que solo se pueden aprender en la adolescencia o en la juventud.

"Se llevó a su casa una de las máquinas de la oficina en medio de las burlas cordiales de los subalternos: "Loro viejo no aprende a bablar". Leona Cassiani, entusiasta de cualquier novedad, se ofreció para darle lecciones de mecanografía a domicilio" (El amor en los tiempos del cólera, 1985, p. 398).

Refranes descriptivos. Este tipo de refranes dan cuenta de un estado de cosas, manifiestan que existen, que son reales, pero no expresan juicios al respecto; por tanto, en esta categoría se incluyen "aquellos refranes que describen o tipifican una conducta, un hecho o situación que se da o puede suceder con frecuencia..." (Zuluaga et al., 2019, p. 22). Algunos ejemplos de este tipo de refranes encontrados en la obra de García Márquez: un clavo saca otro clavo; cría cuervos y te sacarán los ojos; matar el tigre y asustarse con el cuero. Seguidamente un ejemplo con microcontexto de uso:

Ningún borracho se come la mierda. refr. De naturaleza descriptiva y sentido figurado, indica que nadie en sus actos prescinde absolutamente de la razón; nadie es tan inconsciente como para hacerse daño a sí mismo.

“-Es en serio — le dijo Cristo Bedoya—. Lo están buscando para matarlo.

A Victoria Guzmán se le olvidó el candor.

—Esos pobres muchachos no matan a nadie — dijo.

—Están bebiendo desde el sábado — dijo Cristo Bedoya.

—Por lo mismo —replicó ella—: No bay borracho que se coma su

propia caca". (Crónica de una muerte anunciada, 2003, p. 120).

Finalmente presentamos ejemplos de otros enunciados fraseológicos identificados en las novelas de García Márquez: sentencia bíblica y frase célebre.

Sentencia bíblica. Estas son muy frecuentes, pues en algunas novelas del nobel colombiano predomina la dicotomía sagrado/profano ${ }^{3}$. Algunas de las sentencias halladas en la novelística de García Márquez son las siguientes: los últimos serán los primeros; mi reino no es de este mundo; dejad que los niños vengan a mi; echar margaritas a los cerdos. Seguidamente un ejemplo detallado:

A su imagen y semejanza. Sentencia bíblica. De la misma naturaleza, cantidad o calidad de otra cosa o persona.

3 Aspecto señalado en el texto Caracterización de algunos personajes de Gabriel García Márquez a partir de Unidades Fraseológicas Fijas (Zuluaga et al., 2010). 
"-Puesto que su casa fue desde el primer momento la mejor de la aldea, las otras fueron arregladas a su imagen y semejanza" (Cien años de soledad, 2007, p. 14).

Frase célebre. En el corpus fraseológico recolectado identificamos dos frases célebres en la obra de García Márquez: Dadme un punto de apoyo y moveré el mundo y Halcón que se atreve con garza guerrera, peligros espera. Ahora exponemos el microcontexto de esta última:

Halcón que se atreve con garza guerrera, peligros espera. $f r$ : célebre del escritor portugués Gil Vicente. Advierte los peligros de inmiscuirse con alguien que es más audaz o tiene mayor experiencia en algo.

“-Santiago Nasar perdió el sentido desde que la vio por primera vez. Yo lo previne: Halcón que se atreve con garza guerrera, peligros espera. Pero él no me oyó, aturdido por los silbos quiméricos de María Alejandrina Cervantes" (Crónica de una muerte anunciada, 1981, p. 77).

Para finalizar este apartado, hacemos énfasis en que el análisis de las UFF en la obra literaria puede favorecer la interpretación textual y desentrañar diversas connotaciones, puesto que estas unidades

debido tanto a su relación con el acervo de sabiduría popular, que le confiere estabilidad, como a la maleabilidad de su estructura, a raíz de las opciones estilística de los autores, pueden contribuir de varias maneras a la articulación del sentido de un texto literario. (Bobãilã, 2014, p. 94)

En síntesis, lo expuesto anteriormente es solo una muestra de cómo las UFF se pueden integrar al análisis de obras literarias y las posibilidades de investigación lingüística alrededor de este tipo de corpus fraseológico.

\section{Conclusiones}

El análisis de los fraseologismos posibilita una aproximación significativa y significante a la obra literaria, en este caso, a la novelística de Gabriel García Márquez, asunto que permite una aprehensión de la realidad narrativa y discursiva de las obras de dicho escritor; así, el análisis fraseológico de su obra posibilita abordar diversas dimensiones lingüísticas y abrir nuevos ámbitos interpretativos.

A partir de la identificación de las UFF en las novelas de García Márquez, se corrobora que los mecanismos lingüísticos de los textos literarios no difieren de cualquier otro tipo de discurso; es más, mediante el estudio de los primeros se puede lograr un acercamiento significativo a los segundos. Por tanto, se considera que el estudio de las UFF se debe integrar al análisis textual y hermenéutico de la novelística de García Márquez, puesto que, sin duda, estas unidades aportan datos de gran interés a partir de la relación entre lengua, sociedad y cultura. 
En este marco, se debe considerar que el concepto de verosimilitud en la literatura no se restringe a la relación entre lo real y lo textual, sino que admite analizar los aspectos estilísticos y pragmáticos dentro de una determinada obra que son los que, en definitiva, facilitan una comunicación efectiva entre autor y lector, quienes se encuentran en el territorio semántico, pragmático y semiótico del texto.

Lo anterior permite vislumbrar las posibilidades que ofrecen las obras literarias como corpus lingüístico, sobre todo si se tiene en cuenta que en la investigación lingüística es más fácil el acceso a textos literarios, por su naturaleza escrita y, por tanto, perdurable en el tiempo, además de que estos se pueden evidenciar y analizar como actos de simulación del discurso cotidiano.

La tipología presentada no es exhaustiva; no obstante, consideramos que da cuenta de las fórmulas encontradas en el corpus de análisis. Asimismo, en esta investigación se ha partido de una contextualización de las UFF y ha tenido presente no solo el español general, sino también la variedad dialectal en la cual se inscribe buena parte de ellas y con la que se identifica al escritor colombiano.

Finalmente, aunque no se ha realizado un estudio detallado de las UFF en novelas de Gabriel García Márquez, creemos que la ejemplificación presentada consiente entrever el potencial de este tipo de análisis para desentrañar los sentidos del texto literario y las funciones estilísticas, semánticas y pragmáticas de estas unidades.

\section{Referencias}

Bobãilã, I. (2014). Funciones de las unidades fraseológicas en el texto narrativo. Studia UBB Philologia, 59(2), 91-101. http:/www.diacronia.ro/ro/ indexing/details/A15848/pdf

Bolaños, S. et. al. (1990). Los actos de habla y el texto narrativo. Con-textos. Revista de Semiótica Literaria, 1(6), 47-62.

Cabré, M. T. (2003). Teorías de la terminología: de la prescripción a la descripción. En G. Adamo, V. Della Valle (eds.), Innovazione lessicale e terminologie specialistiche, 92 (pp. 168-188). Leo S. Olschki Editore. http://www.upf. edu/pdi/dtf/teresa.cabre/docums/ca03te.pdf

Cabré, M. T. (2007). Constituir un corpus de textos de especialidad: condiciones y posibilidades. En M. Ballard, C. Pineira-Tresmontant (eds.), Les corpus en linguistique et en traductologie (pp. 89-106). Artois Presses Université. http://www.upf.edu/pdi/dtf/teresa.cabre/docums/ca07arra.pdf

Corpas, G. (1996). Manual de fraseología española. Gredos.

Coseriu, E. (1986). Principios de semántica estructural. Gredos.

De Jonge, B. (2001). Spanish Subjunctive Mood: One Form, more than One Meaning. Proceedings from the Fifth Colloquium on Romance Linguistics, 79-92. 
De Oliveira, M. (2007). La lengua ladina de García Márquez. Panamericana.

Díaz, B. \& Hernández, M. (2010). Aproximación a los fraseologismos. El refrán, origen y presencia en la literatura. El ejemplo cubano. Revista Avanzada Científica, $13(2)$.

Díaz, V., Zuluaga, F. \& Ciro, L. (2009). Funciones de los fraseologismos en la novelística de García Márquez: el caso de la desautomatización. Revista Virtual Universidad Católica del Norte, 26. https://revistavirtual.ucn. edu.co/index.php/RevistaUCN/article/view/112/225

Eco, U. (1996). Seis paseos por los bosques narrativos. Lumen.

Fernández, C. (2000). Una aproximación pragmática al estudio del texto literario: propuesta de análisis de Betrayal desde las teorías de la cortesía y de la relevancia. ELIA I, Estudios de Lingüistica Inglesa Aplicada, (1),107-117. http://revistas.uned.es/index.php/ELIA/article/view/18282/15353

Gancedo, M. (2016). El texto dramático literario como corpus para el análisis histórico de las actividades de imagen. Textos en Proceso 2(1), 162-173. https://doi. org/10.17710/tep.2016.2.1.8gancedoruiz

García Márquez, G. (1985), El amor en los tiempos del cólera. Oveja Negra.

García Márquez, G. (1989), El general en su laberinto. Oveja Negra.

García Márquez, G. (1993). El coronel no tiene quien le escriba. Espasa Calpe.

García Márquez, G. (1994), Del amor y otros demonios. Norma.

García Márquez, G. (2003). Crónica de una muerte anunciada. Norma.

García Márquez, G. (2003). El otoño del patriarca. Norma.

García Márquez, G. (2003). La bojarasca. Norma.

García Márquez, G. (2004), Memoria de mis putas tristes. Grupo Editorial Norma, Mondadori.

García Márquez, G. (2007). Cien años de soledad. Edición Conmemorativa. Real Academia Española, Asociación de Academias de la Lengua Española.

Haensch, G. \& Werner, R. (1993). Nuevo Diccionario de Colombianismos (NDCol). Instituto Caro y Cuervo.

Kareem Alshamary, S. (2018). Las frases hechas en la Crónica de una muerte anunciada de Gabriel García Márquez y su traducción árabe. Monográficos Sinoele, 17, 899-912.

Kristeva, J. (1978a). Semiótica 1. Editorial Fudamentos. 
Kristeva, J. (1978b). Semiótica 2. Editorial Fudamentos.

López, V. (2012). La pertinencia del corpus literario en el aula de ELE: una propuesta basada en la descripción, la narración y la argumentación. (Tesis de Maestría). Université de Montréa. https://core.ac.uk/download/ pdf/55648969.pdf

McCullough, J. (2001). Los usos de los córpora de textos en la enseñanza de lenguas. En M. Trenchs (ed.), Nuevas tecnologías para el autoaprendizaje y la didáctica de lenguas (pp. 125-140). Milenio.

Palma, S. (2010). Las expresiones fijas en Cien años de soledad. Journée d'étude des bispanistes sur le thème de la solitude.

Pérez, C. (2002). Explotación de los córpora textuales informatizados para la creación de bases de datos terminológicas basadas en el conocimiento. Estudios de Lingüística del Español (ELiEs), 18. http://ddd.uab.cat/pub/elies/elies a2002v18/431.html

Ramírez, R. \& Álvarez, T. (2006). Aproximación a un análisis pragmático del refrán: dimensión argumentativa. Didáctica (Lengua y Literatura), 18, 221-23.

Real Academia Española y Asociación de Academias de la Lengua Española. (2009). Nueva gramática de la lengua española (NGLE). Morfología-sintaxis I. Espasa Calpe.

Real Academia Española. (2014). Diccionario de la lengua española (DLE). Espasa Calpe.

Ruiz-Gurillo, L. (1997). Análisis de un corpus fraseológico de "Cien años de soledad": sus locuciones adverbiales. En Gallardo B. et al. En Panorama de la investigació lingüística a l'Estat espanyol: actes del I congrés de lingüística general, 5, 62-70.

Searle, J. (1979), Expression and Meaning. Cambridge University Press.

Searle, J. (1996). El estatuto lógico del discurso de ficción. Íkala, Revista de Lenguajey Cultura, 1(1/2), 159-180. https://doi.org/10.1017/CBO9780511609213

Seco, M., Andrés, 0. \& Ramos, G. (2004), Diccionario fraseológico documentado del español actual. Locuciones y modismos españoles (DFEA). Aguilar.

Sevilla Muñoz, J. (2000). El refranero hoy. Paremia, 9, 133-142.

Tarnovska, 0. (2003). Consideraciones acerca del mínimo paremiológico español. (Tesis doctoral). Universidad de Granada.

Van Dijk, T. (1987). La pragmática de la comunicación literaria. En J. Mayoral (comp.), Pragmática de la comunicación literaria (pp. 171-194). Arco. 
http://www.discursos.org/Art/La\%20pragm\%E1tica\%20de $\% 20$ la $\% 20$ comunicaci $\%$ F3n\%20literaria.pdf

Zuluaga, A. (1980). Introducción al estudio de las expresiones fijas. Peter Lang.

Zuluaga, A. (1992). Spanische Phraseologie. Lexikon der Romanistischen Linguistik, 6(1), 125-131.

Zuluaga, A. (1997). Sobre las funciones de los fraseologismos en textos literarios. Paremia, 6, 631-640.

Zuluaga, F., Díaz, V. \& Ciro, L. (2010). Caracterización de algunos personajes de Gabriel García Márquez a partir de unidades fraseológicas fijas. Crítica.cl. Revista Latinoamericana de Ensayo. https://critica.cl/literatura/caracterizacionde-algunos-personajes-de-gabriel-garcia-marquez-a-partir-deunidades-fraseologicas-fijas.

Zuluaga, F., Díaz, V. \& Ciro, L. (2019). Dichos, refranes y locuciones en las novelas de Gabriel García Márquez. Instituto Caro y Cuervo. 